\title{
Regulating inflammation through the anti-inflammatory enzyme platelet-activating factor-acetylhydrolase
}

\author{
H ugo C Castro Faria Neto, Diana M Stafforini*, Stephen M Prescott*, \\ Guy A Zimmerman*/+
}

\begin{abstract}
Laboratório de Imunofarmacologia, Departamento de Fisiologia e Farmacodinâmica, Instituto Oswaldo Cruz-Fiocruz, Rio de Janeiro, RJ, Brasil *Program in Human Molecular Biology and Genetics, the Huntsman Cancer Institute (SMP, DMS), MD, 15 North 2030 East, Building 533, Room 4220, University of Utah, Salt Lake City, UT 84112, US

Platelet-activating factor $(P A F)$ is one of the most potent lipid mediators involved in inflammatory events. The acetyl group at the sn-2 position of its glycerol backbone is essential for its biological activity. Deacetylation induces the formation of the inactive metabolite lyso-PAF. This deacetylation reaction is catalyzed by PAFacetylhydrolase (PAF-AH), a calcium independent phospholipase $A_{2}$ that also degrades a family of PAF-like oxidized phospholipids with short sn-2 residues. Biochemical and enzymological evaluations revealed that at least three types of PAF-AH exist in mammals, namely the intracellular types I and II and a plasma type. Many observations indicate that plasma PAF AH terminates signals by PAF and oxidized PAF-like lipids and thereby regulates inflammatory responses. In this review, we will focus on the potential of PAF-AH as a modulator of diseases of dysregulated inflammation.
\end{abstract}

Key words: platelet-activating factor - platelet-activating factor -acethylhydrolase - inflammatory disease - sepsis

Platelet-activating factor (PAF) is an important mediator of juxtacrine and paracrine signals between cells (Zimmerman et al. 1990, Lorant et al. 1991, Stafforini et al. 2003), but in some cases, PAF may also have endocrine, autocrine, and intercrine signaling roles (Bazan et al. 1991, Prescott et al. 2000). PAF is synthesized by a variety of cell types, including macrophages, endothelial cells, neutrophils, basophils, eosinophils, and fibroblasts (Prescott et al. 2000), many of which are central to the inflammatory and hemostatic systems. The enzymatic synthesis of PAF is highly regulated and most commonly involves a twostep mechanism. The first is the hydrolysis of long chain fatty acids esterified at the $s n-2$ position in the glycerol backbone of ether phospholipids and is catalyzed by cytosolic phospholipase $\mathrm{A}_{2}$; subsequently the product of this hydrolysis (lyso-PAF) is acetylated by an acethyltransferase to produce bioactive PAF (Snyder et al. 1985). The biological effects of PAF are mediated by binding to a G-protein coupled receptor that specifically recognizes PAF and related PAF-like lipids (Honda et al. 1991, McIntyre et al. 1999). The murine PAF receptor has been deleted by homologous recombination and also overexpressed, yielding important insights into the biological and pathophysiologic roles of the PAF signaling system (Nagase et al. 1997, Ishii et al. 1998). Several mechanisms regulate the PAF signaling system. These include tightly controlled synthetic pathways, spatial regulation of the display of PAF, cell-specific expression of the receptor for PAF, homologous and heterologous desensitization of the receptor, and rapid degradation of PAF by

+Corresponding author. E-mail: guy.zimmerman@hmbg.utah.edu Received 8 November 2004

Accepted 30 December 2004 extracellular and intracellular acetylhydrolases. For instance, homologous desensitization after repeated exposure to PAF, a control mechanism that potentially limits its signaling actions, was used to characterize specific actions of PAF before the development of highly selective competitive antagonists (Zimmerman et al. 1985, Cordeiro et al. 1986). Together, the redundant regulatory mechanisms appear to have evolved to precisely control biologic activities of PAF. Thus, unregulated or dysregulated signaling by PAF can be a mechanism of disease. In this review, we will focus on the importance of plasma $\mathrm{PAF}-\mathrm{AH}$ as a regulatory mechanism in PAF signaling pathways.

\section{Subtypes and biochemical properties of PAF-AH}

PAF-AH (EC 3.1.1.47) was identified as an enzyme that hydrolyzes an acetyl ester at the $s n-2$ position of PAF, inactivating it to 1-O-alkyl-sn-glycero-3-phosphocholine (lysoPAF) (Blank et al. 1981). To date, three isoforms of PAF-AH have been identified: plasma PAF-AH and PAFAH II and Ib. Plasma PAF-AH is a monomeric polypeptide with a molecular weight of $45 \mathrm{kDa}$. PAF-AH II is an intracellular enzyme with a molecular weight of $40 \mathrm{kDa}$. This enzyme is highly expressed in liver and kidney, and shares $41 \%$ sequence identity with plasma PAF-AH (Hattori et al. 1995). Another intracellular form of PAF-AH, the PAFAH Ib complex, has been found in bovine brain and consists of two $26 \mathrm{kDa}$ catalytic subunits, a1 and a2, which share $63 \%$ sequence identity with each other, and a regulatory 45-kDa b-subunit which is the product of the MillerDieker lissencephaly gene (Hattori et al. 1994). PAF-AH Ib displays high specificity for the $s n-2$ acetyl group of a phosphoglyceride while Plasma PAF-AH and PAF-AH II preferentially hydrolyse PAF analogs with $s n-2$ propionyl and butyroyl moieties (Hattori et al. 1995). A loss-of-function mutation in the plasma PAF-AH gene is reported in $4 \%$ of Japanese people, and an association of inherited 
plasma PAF-AH deficiency with inflammatory diseases has been demonstrated (Stafforini et al. 1996, Yamada \& Yokota 1997). Exogenously added PAF has a half-life of only 5 min in the plasma of normal subjects, whereas more than $95 \%$ of the PAF remained unchanged after 15 min in the plasma from plasma PAF-AH-deficient subjects (Stafforini et al. 1987, Yoshida et al. 1996), indicating that plasma PAF-AH is mainly responsible for degradation of PAF in human blood. In human plasma, PAF-AH is tightly associated with both high and low density lipoprotein (HDL and LDL) (Stafforini et al. 1987, Yamada et al. 1994), whereas in rodents plasma PAF-AH is mainly bound to HDL (Pritchard 1987). In contrast to most phospholipase A2 enzymes, PAF-AHs do not require $\mathrm{Ca}^{2+}$ for enzymatic activity (Stafforini et al. 1987). The human plasma enzyme PAF-AH is extensively N-glycosylated and can be inhibited by serine protease inhibitors such as diisopropyl fluorophosphate (DFP). The purified plasma PAF-AH shows a $\mathrm{Km}$ value that is greater than the PAF level in human plasma under physiological and pathological conditions. Nevertheless, this enzyme has an activity (Vmax $=170 \mathrm{~mol} / \mathrm{min} / \mathrm{mg}$ ) sufficient for hydrolysis of PAF even at very low concentrations (Stafforini et al. 1987).

As mentioned earlier, plasma PAF-AH substrate speci- ficity decreases when the $s n-2$ residue is lengthened. Plasma PAF-AH hardly hydrolyzes phosphatidylcholine with a C9 acyl chain, but the enzyme activity is dramatically increased in the presence of an aldehyde group at the $o$-end of the acyl chain (Stremler et al. 1991). In addition, 1-Palmitoyl-2 (5-oxovaleroyl)-sn-glycero-3phosphocholine and 1-palmitoyl-2-glutaroyl-sn-glycero3-phoshocholine, products of oxidized 1-palmitoyl-2arachidonoyl-sn-glycero-3-phosphocholine, and 1Ohexadecyl-2-(butanoyl or butenoyl)-sn-glycero-3phosphocholines, PAF receptor agonists found in oxidized LDL are also efficiently hydrolyzed by plasma PAFAH, as shown in Fig. 1 (Stremler et al. 1991, Stafforini et al. 1997, Marathe et al. 1999). Importantly, all these substrates have potent biological effects and may contribute to pathological events when they accumulate inappropriately (Prescott et al. 2000). A phosphate group is not essentially required for hydrolysis by PAF-AH since some shortchain diacylglycerols and triacylglycerols can be hydrolyzed by the enzyme. Therefore, it seems that the minimal structural requirement for a plasma PAF-AH substrate may be the portion of a glyceride derivative that includes a $s n$ 2 ester, and a reasonably hydrophobic chain in the position occupied by the $s n-1$ chain (Min et al. 2001).

A

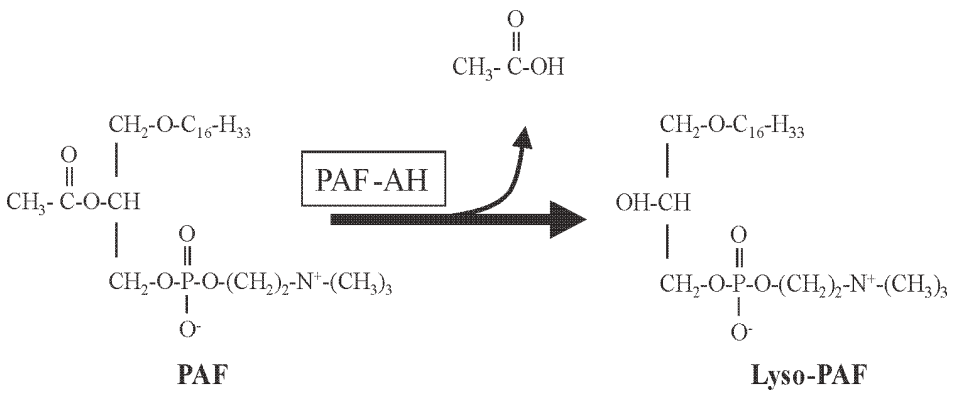

B butenoyl-PAF $(16: 0 \mathrm{e} / 4: 1-\mathrm{PC})$

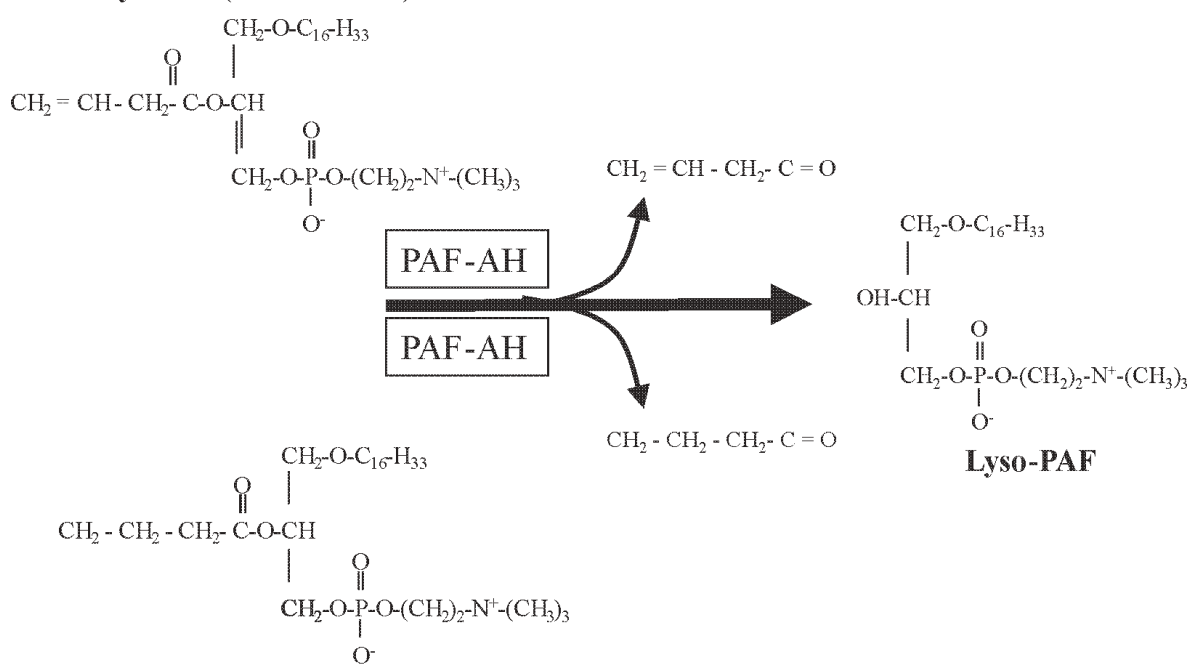

butanoyl-PAF (16:0e/4:0-GPC)

Fig. 1: PAF-AH hydrolyzes PAF and oxidized PAF-like lipids to their inactive metabolite Lyso-PAF. A: hydrolysis of $s n-2$ bound acetate of PAF inactivates it to Lyso-PAF; B: hydrolysis of $s n-2$ bound oxidatively fragmented arachidonoyl residues of butenoyl or butanoyl PAFlike lipids to Lyso-PAF. 


\section{PAF-AH gene, regulation of its expression and gene polymorphism}

Tjoelker et al. (1995) cloned the human plasma PAFAH cDNA by screening a human macrophage cDNA library. The encoded protein is composed of 441 amino acid residues. The gene for human plasma PAF-AH is mapped at chromosome 6p12-21.1 and comprises 12 exons (Stafforini et al. 1996). The primary structure of plasma PAF-AH is unique and includes a small region of homology, a GXSXG motif. An active site triad, formed by Ser273 with His-351 and Asp-296 is critical for its catalytic properties and is similar to that in several neutral lipases (Tjoelker et al. 1995). The presence of the GXSXG motif in plasma PAF-AH is consistent with observations that the enzyme activity can be blocked by the active site Serspecific inhibitor, diisopropyl fluorophosphate.

In vitro studies have identified hematopoietic cells and hepatocytes as the source of plasma PAF-AH. Macrophages synthesize and secrete plasma PAF-AH activity during differentiation from monocytes to macrophages (Elstad et al. 1989, Narahara et al. 1993, Wu et al. 2004). The increase in the synthesis and secretion of plasma PAF-AH during differentiation from monocytes to macrophages can be seen as a mechanism of control of acute inflammation. In addition, plasma PAF-AH may also serve as a marker for macrophage differentiation in experimental models and clinical syndromes. The remarkable difference in plasma PAF-AH mRNA expression between monocytes and macrophages is likely to be the result of plasma PAF$\mathrm{AH}$ promoter regulation (Cao et al. 1998). Nucleotide sequence of $3.5 \mathrm{~kb} 5$ ' to the transcription initiation site reveals numerous cis-acting promoter elements, including Sp1 sites, MS2 binding consensus sequences, MS1 site, Pu. 1 box and STAT binding consensus sequences (Cao et al. 1998, Karasawa et al. 2003). Recently, Wu et al. (2004) showed that the ability of LPS to induce transcriptional activation of PAF-AH involves enhanced transactivation function of Sp1 via $\mathrm{p} 38$-MAPK activation.

In addition to macrophages, other hematopoietic cells such as mast cells also secrete plasma PAF-AH in response to the inflammatory stimuli (Nakajima et al. 1997). Recently, Asano et al. (1999) analyzed subjects who had received an allogeneic bone marrow transplant and demonstrated that PAF-AH activity in plasma depended on the donor's, but not on the recipient's genotype, confirming that PAF$\mathrm{AH}$ activity in plasma originates from hematopoietic stem cell-derived cells such as macrophages, but not from hepatocytes. The expression of plasma PAF-AH mRNA and production of plasma PAF-AH protein are increased in the resident macrophages of the liver in response to LPS exposure (Howard et al. 1997). Up-regulation of the plasma PAF-AH expression appears to be an important mechanism for elevating the local and systemic ability to inactivate PAF and oxidized phospholipids in order to minimize PAF-mediated pathophysiology resulting from exposure to LPS (Howard \& Olson 2000). However, in mouse models of endotoxemia and bacterial sepsis, plasma activity of PAF-AH is significantly decreased within $24 \mathrm{~h}$ after the challenge and then returns to baseline in surviving animals (Gomes et al., unpublished data). One possible ex- planation for this discrepancy is that the massive amounts of PAF produced under endotoxic and septic conditions is down modulating the expression of the PAF-AH since PAF itself was shown to inhibit the secretion of PAF-AH by macrophages through a calcium-dependent mechanism (Narahara et al. 2003). Nevertheless, we have observed that PAF induces, rather than inhibits, PAF-AH expression in macrophages using a PAF-AH reporter construct and a different subset of macrophages (Cao et al. 1998), indicating that the effect of PAF on PAF-AH expression is variable, depending on the macrophage type and the experimental conditions. Another distinct possibility is that PAF-AH activity in sepsis appears to be time-dependent, for example, activity can be rapidly depressed and then come back to normal or supra normal values (Gomes et al., unpublished data). All together, these evidence indicate that the PAF-AH gene contains elements that confer responsiveness to inflammatory challenge.

Autosomal recessive deficiency of plasma PAF-AH activity in Japanese families was first reported Miwa et al. (1988), and later this was showed to be due to a loss-of function mutation (Val279Phe, exon 9, position 994; $\mathrm{G} \rightarrow \mathrm{T}$ ) in the plasma PAF-AH gene (Stafforini et al. 1996). Another loss-of-function mutation (Gln281 Arg, exon 9, position 1001, $\mathrm{A} \rightarrow \mathrm{G}$ ) is also found in the Japanese population (Yamada \& Yokota 1997). The incidence of the V279F mutation is reported to be high in healthy Japanese with heterozygous and homozygous frequencies of 27 and $4 \%$, respectively (Stafforini et al. 1996). Although this mutation has previously been reported exclusively in the Japanese population, later on it was reported also in Kirghiz and Turkish populations (Balta et al. 2001). The identification of genetic lesions that abolish plasma PAF-AH activity was an important step towards the investigation of the role of this enzyme in diseases. Indeed, PAF-AH mutations have been associated with several diseases with inflammatory background including, asthma, atherosclerosis, myocardial infarction, and dilated cardiomyopathy (Karasawa et al. 2003).

\section{PAF-AH in diseases and disease models}

Many in vitro and in vivo observations indicate that plasma PAF-AH regulates inflammation by terminating signals triggered by PAF and oxidized PAF-like lipids (Imaizumi et al. 1995, Prescott et al. 2000, Stafforini 2001). In fact, upon cloning it was demonstrated that the recombinant form of plasma PAF-AH blocks inflammatory responses triggered by administration of exogenous PAF to experimental animals (Tjoelker et al. 1995). Additionally, deficiency of plasma PAF-AH due to a genetic mutation (see above) is correlated with severity or negative outcomes in several inflammatory and/or thrombotic and cardiovascular diseases such as asthma (Stafforini 2001), necrotizing enterocolitis (Imaizumi et al. 1995), myocardial infarction (Yamada et al. 1998), stroke (Hiramoto et al. 1997), non-familial dilated cardiomyopathy (Ichihara et al. 1998), and cerebral hemorrhage (Yoshida et al. 1998). Moreover, the prevalence of the mutant genotype (V279F) was significantly more frequently in patients with atherosclerotic occlusive disease than in control subjects (Unno et al. 2000). Therefore, loss-of-function mutations leading to 
hereditary deficiency of plasma PAF-AH activity may contribute to the spectrum of severity in inflammatory syndromes.

Studies in experimental animals and humans indicate that PAF may be an important mediator of asthma. PAF promotes eosinophil recruitment to sites of allergic inflammation through activation of the eosinophil adhesion molecules and through direct and indirect chemotactic effect (Silva et al. 1989, e Silva et al. 1991, Martins et al. 1993). In a murine model of allergen-induced asthma, the administration of recombinant plasma PAF-AH had a marked effect on late-phase pulmonary inflammation, which included a significant reduction in airway eosinophil infiltration, mucus secretion, and airway hyperreactivity in response to methacholine (Henderson et al. 2000). Moreover, Stafforini et al. (1999) reported that the prevalence of the V279F mutation in asthmatic subjects was higher than in Japanese healthy controls and that the severity of asthma was highest in homozygous-deficient subjects. By contrast, conflicting results were also reported in the study by Satoh et al. (1999) where the allele frequency of the V279F mutation in patients with asthma was not distinct from that in Japanese healthy controls. Also, a phase II study showed that the administration of human recombinant plasma PAF-AH to atopic subjects with mild asthma failed to reduce either earlier- or lateasthmatic response to bronchial allergen challenge (Henig et al. 2000). This discrepancy between pre-clinical studies and the negative phase II trials is largely unexplained, but it is possible that dose and route of administration of recombinant plasma PAF-AH may not have been adequate. Furthermore, clinical asthma is an heterogeneous syndrome with several stages; thus, the appropriate patient subgroup may not have been identified.

In addition to asthma, numerous studies have suggested an involvement of PAF in the pathology of systemic anaphylaxis. Most manifestations of the anaphylactic shock are reproduced by an injection of PAF into animals (Martins et al. 1987, Imaizumi et al. 1995), and high levels of PAF have been detected in the serum of rodent anaphylactic models (Pinckard et al. 1979). Also, PAF-receptor knock-out mice showed lower mortality than wildtype controls after antigen challenge (Ishii et al. 1998). Consistent with this, recombinant plasma PAF-AH improved the mortality in PAF-induced and antigen-induced anaphylactic shock models in mice (Fukuda et al. 2000), suggesting that excessive PAF generation is causing dysregulated anaphylactic inflammation that can be controlled by recombinant plasma PAF-AH.

PAF has also been shown to significantly participate in myocardial reperfusion injury (Loucks et al. 1997). In that respect, important biological activities of PAF include neutrophil activation and chemotaxis, alterations in vascular permeability and platelet activation (Martins et al. 1988, 1989, Zimmerman et al. 1990). Here again, pre-clinical data indicate that administration of recombinant plasma PAF-AH reduced myocardial injury induced by ischemia/ reperfusion in rabbits by regulating exacerbated inflammation (Morgan et al. 1999). The roles of endogenous PAF-AH in atherosclerotic complications have recently been reviewed (Eisaf \& Tselepis 2003, Chen 2004).
Another important syndrome of dysregulated inflammation is sepsis. Sepsis is one of the most frequent causes of death in intensive-care patients worldwide. In the United States alone approximately 700,000 people are affected annually and 210,000 deaths are accounted for (Angus \& Wax 2001, Martin et al. 2003). The currently definition for sepsis states that this syndrome is the intersection between systemic inflammatory responses (SIRS) and the presence of infection (Bone et al. 1992), but more recently sepsis is being considered a consequence of poorly regulated innate immune response to microbial products (Glauser 2000). Widespread activation of cells responsive to pathogens results in uncontrolled systemic inflammation with the release of an array of inflammatory mediators including cytokines, reactive oxygen species and lipid mediators such as PAF. These factors in combination can induce vascular dilatation and increase in permeability with leakage of plasma components, and extravasation and activation of leukocytes to tissues and organs. In addition, inflammatory mediators and pathogen components will also activate the coagulation system causing disseminated intravascular coagulation. Together, those effects will lead to hypoperfusion and tissue hypoxia that apparently are the main cause of organ dysfunction, which represents the often-lethal stage of sepsis (Riedemann et al. 2003, Van Amersfoort et al. 2003).

There are substantial evidence to believe that PAF or PAF-like lipids are central effectors in the sepsis syndrome (Mathiak et al. 1997, Tetta et al. 1997, Zimmerman \& McIntyre 2004). Among these is evidence that PAF contributes to acute sequestration of neutrophils and their adhesion to endothelial cells (Bozza et al. 1994, Zimmerman et al. 1996) as well as their accumulation in the site of inflammation (Bozza et al. 1994) after endotoxin (lipopolysaccharide) administration. A provocative observation is that overexpression of the PAF receptor increases lethality in response to lipopolysaccharide administration in mice (Nagase et al. 1997), although animals made genetically deficient in the PAF receptor remained susceptible to endotoxin with vascular and cytokine responses equivalent to wild type controls (Ishii et al. 1998).

In humans, an initial observation was the presence of intravascular PAF activity in children with sepsis (Bussolino et al. 1987). Another early study demonstrated that there was increased bioactivity characteristic of PAF in samples from septic patients when compared with controls (Lopez Diez et al. 1989). In subsequent studies, increased PAF bioactivity was also reported in plasma samples from patients with bacteremia compared with blood from control subjects (Heuer 1991). Despite encouraging results with PAF receptor antagonists in animal models of endotoxemia and sepsis (Chang et al. 1987, 1990, Rabinovici et al. 1990), most of the clinical trials conducted with these drugs have not confirmed the benefits of these drugs in humans (Dhainaut et al. 1998, Suputtamongkol et al. 2000). Importantly, Graham et al. (1994) reported decreased PAF-AH plasma activity in blood samples from septic patients and that the half-life of PAF was prolonged in the plasma of septic patients who died compared to survivors or normal volunteers. We have confirmed this observation and expanded it to show that PAF-AH plasma 
activity was also decreased in a time dependent fashion in models of endotoxemia and meningococcemia in mice (Fig. 2). In each of these models, there was an initial decrease in the levels of PAF-AH activity that persisted up to $48 \mathrm{~h}$. At later time points, there was a recovery in the levels of PAF-AH activity in surviving animals. In addition, the data illustrate variability in PAF-AH activity levels over time and triggered by different inflammatory and infectious challenges that may be relevant to variability in PAF-AH activity levels in sepsis in humans. One potential mechanism for decreased plasma PAF-AH activity is inactivation of the enzyme by oxidation (Ambrosio et al. 1994, Stafforini et al. 1997). Therefore, in conditions of shock or in the cellular environment of septic inflammation, oxidants may induce synthesis of PAF or generation of oxidized phospholipid and concomitantly inactivate plasma PAF-AH.

Based on those results we have hypothesized that recombinant PAF-AH could be used to replace the endogenous activity to normal or increased levels and that

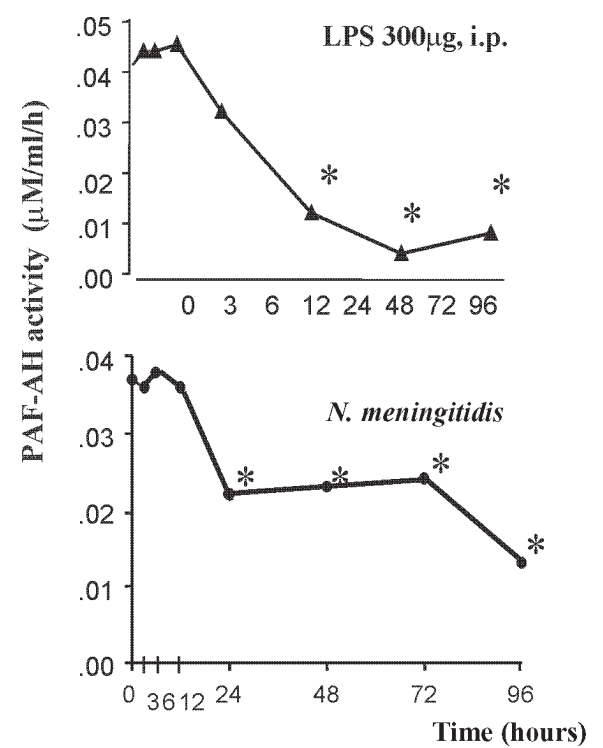

Fig. 2: plasma PAF-AH activity at different time points after the challenge of mice with LPS, or a virulent strain of Neisseria meningitidis (serogroup B N44/89).

this procedure would have beneficial effects on sepsis syndrome. In fact, treatment with recombinant PAF-AH reduced systemic inflammation and death in surrogate models of sepsis and endotoxemia (Gomes et al., unpublished data). These results suggest that PAF-AH may play a key role in the control of dysregulated inflammatory responses triggered during bacterial infections and provide additional evidence that plasma PAF-AH is a terminator of inflammatory signals in humans. However, despite the remarkable protective effect shown by the administration of recombinant PAF-AH to septic patient in an initial phase II clinical study (23\% mortality reduction) (Schuster et al. 2003), a larger phase III study did not confirm this effect (Opal et al. 2004). The reasons for the difference in the Phase II and Phase III results remain to be determined, and likely involve the multiple challenges inherent to sepsis trials. In addition, subsets of septic patients (i.e. those with depressed levels of endogenous PAF-AH rather than those in whom it was returned to normal or supra-normal levels) may be the best candidates for treatment with the recombinant enzyme. As an additional variable, there is evidence that the severity of sepsis influences the efficacy of blocking therapies and that a positive effect of PAF-AH may have been less readily detected in the phase III trial (Minneci et al. 2004). Moreover, multiple, redundant pathophysiological components appear to be simultaneously activated in sepsis, and it is unlikely that therapy directed at any one of them will dramatically improve survival in the clinical setting. Rather, a combination of therapies directed at many arms of the

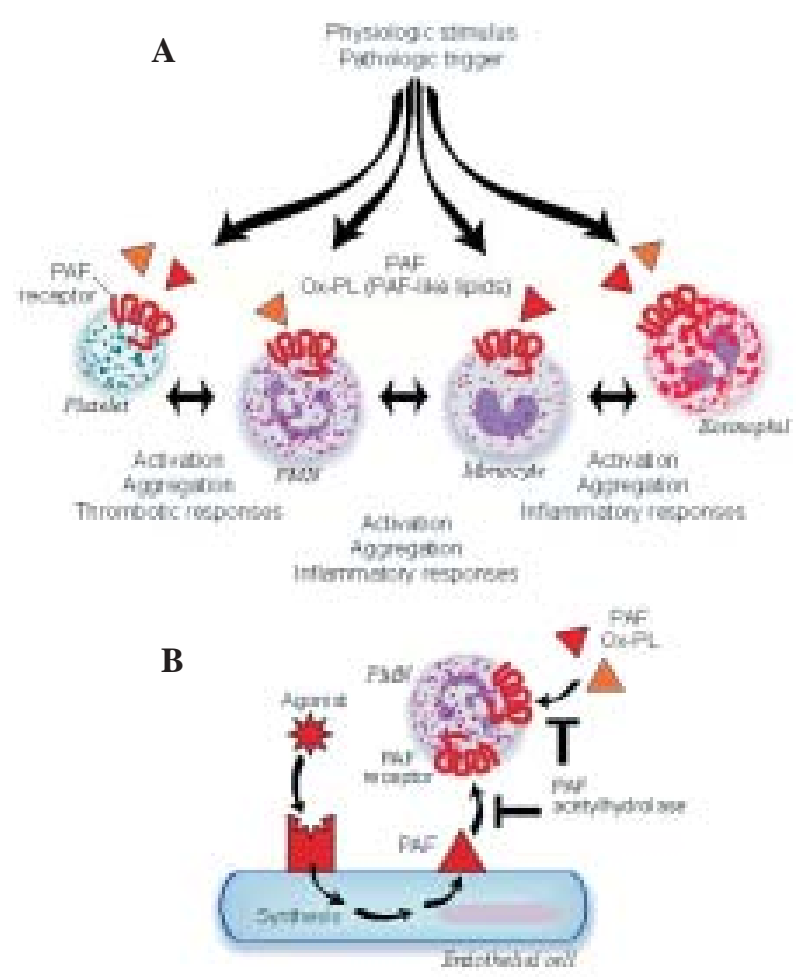

Fig. 3: the PAF Signaling System Mediates Activation Responses in Inflammation and Thrombosis. A: the PAF signaling system includes a cell surface receptor that is constitutively present on the plasma membranes of platelets and a variety of leukocyte subtypes and intracellular signal transduction pathways that are linked to the PAF receptor via $G$ proteins and other molecular intermediates. Engagement of the PAF receptor by its ligands, PAF and certain structurally-similar PAF-like oxidatively modified phospholipids (Ox-P1), induces functional responses in these target cells and others. In some physiologic and pathologic circumstances the PAF signaling system links the inflammatory and thrombotic cascades; $\mathrm{B}$ : cellular activities triggered by the PAF signaling system are regulated by several mechanisms, as illustrated in the specific example of synthesis of PAF by human endothelial cells and its activation of target polymorphonuclear leukocytes (PMNs). These regulatory mechanisms include a tightly controlled synthetic pathway, PAF receptor expression on specific target cells, juxtacrine activation of target cells by membrane-associated PAF (spatial regulation of signaling ) and degradation of PAF and Ox-Pl by cellular and plasma enzymes, the PAF acetylhydrolases. See text and cited references for details. 
septic process, may prove to be the best approach and rPAF-AH may prove to be a valuable tool in specific conditions.

\section{Concluding remarks}

The PAF signaling system is specialized for information transfer in the inflammatory and thrombotic systems, in addition to mediating responses of several other cell types (Zimmerman et al. 2002). One important feature is the expression of the PAF receptor on both platelets and innate immune effector cells. Signaling via the PAF receptor induces homeostatic cellular responses but there is also extensive experimental and clinical evidence that PAF signaling can mediate pathologic events if it is dysregulated, and that this is a mechanism of disease. One way that PAF signaling can become dysregulated is by depression or failure of endogenous regulatory checkpoints that limit the biologic activities of the PAF signaling system. Our studies and those of others outlined in this review identify plasma PAF-AH as one of the key regulatory factors involved, and show that its levels are modulated in inflammation and injury induced by sepsis and other pathologic conditions (Fig. 3). These observations provide new insights into molecular control in inflammatory responses and provide additional evidence that the PAF signaling system is a critical component in innate immune pathways and their links to hemostasis and thrombosis.

\section{REFERENCES}

Ambrosio G, Oriente A, Napoli C, Palumbo G, Chiariello P, Marone $\mathrm{G}$ et al. 1994. Oxygen radicals inhibit human plasma acetylhydrolase, the enzyme that catabolizes platelet-activating factor. J Clin Invest 93: 2408-2416.

Angus DC, Wax RS 2001. Epidemiology of sepsis: an update. Crit Care Med 29: S109-116.

Asano K, Okamoto S, Fukunaga K, Shiomi T, Mori T, Iwata M et al. 1999. Cellular source(s) of platelet-activating-factor acetylhydrolase activity in plasma. Biochem Biophys Res Commun 261: 511-514.

Balta G, Gurgey A, Kudayarov DK, Tunc B, Altay C 2001. Evidence for the existence of the PAF acetylhydrolase mutation (Val279Phe) in non-Japanese populations: a preliminary study in Turkey, Azerbaijan, and Kyrgyzstan. Thromb Res 101: 231-234.

Bazan NG, Squinto SP, Braquet P, Panetta T, Marcheselli VL 1991. Platelet-activating factor and polyunsaturated fatty acids in cerebral ischemia or convulsions: intracellular PAFbinding sites and activation of a fos/jun/AP-1 transcriptional signaling system. Lipids 26: 1236-1242.

Blank ML, Lee T, Fitzgerald V, Snyder F 1981. A specific acetylhydrolase for 1-alkyl-2-acetyl-sn-glycero-3phosphocholine (a hypotensive and platelet-activating lipid). J Biol Chem 256: 175-178.

Bone RC, Balk RA, Cerra FB, Dellinger RP, Fein AM, Knaus WA et al. 1992. Definitions for sepsis and organ failure and guidelines for the use of innovative therapies in sepsis. The ACCP/SCCM Consensus Conference Committee. American College of Chest Physicians/Society of Critical Care Medicine. Chest 101: 1644-1655.
Bozza PT, Castro-Faria-Neto HC, Silva AR, Larangeira AP, Silva PM, Martins MA et al. 1994. Lipopolysaccharideinduced pleural neutrophil accumulation depends on marrow neutrophils and platelet-activating factor. Eur $J$ Pharmacol 270: 143-149.

Bussolino F, Porcellini MG, Varese L, Bosia A 1987. Intravascular release of platelet activating factor in children with sepsis. Thromb Res 48: 619-620.

Cao Y, Stafforini DM, Zimmerman GA, McIntyre TM, Prescott SM 1998. Expression of plasma platelet-activating factor acetylhydrolase is transcriptionally regulated by mediators of inflammation. J Biol Chem 273: 4012-4020.

Chang SW, Feddersen CO, Henson PM, Voelkel NF 1987. Platelet-activating factor mediates hemodynamic changes and lung injury in endotoxin-treated rats. J Clin Invest 79: 14981509.

Chang SW, Fernyak S, Voelkel NF 1990. Beneficial effect of a platelet-activating factor antagonist, WEB 2086, on endotoxin-induced lung injury. Am J Physiol 258: H153-158.

Chen CH 2004. Platelet-activating factor acetylhydrolase: is it good or bad for you? Curr Opin Lipidol 15: 337-341.

Cordeiro RS, Martins MA, Silva PM, Faria Neto HC, Castanheira JR, Vargaftig BB 1986. Desensitization to PAFinduced rat paw oedema by repeated intraplantar injections. Life Sci 39: 1871-1878.

Dhainaut JF, Tenaillon A, Hemmer M, Damas P, Le Tulzo Y, Radermacher P et al. 1998. Confirmatory platelet-activating factor receptor antagonist trial in patients with severe gram-negative bacterial sepsis: a phase III, randomized, double-blind, placebo-controlled, multicenter trial. BN 52021 Sepsis Investigator Group. Crit Care Med 26: 19631971.

e Silva PM, Martins MA, Faria Neto HC, Cordeiro RS, Vargaftig BB 1991. Generation of an eosinophilotactic activity in the pleural cavity of platelet-activating factor-injected rats. $J$ Pharmacol Exp Ther 257: 1039-1044.

Eisaf M, Tselepis AD 2003. Effect of hypolipidemic drugs on lipoprotein-associated platelet activating factor acetylhydrolase. Implication for atherosclerosis. Biochem Pharmacol 66: 2069-2073.

Elstad MR, Stafforini DM, McIntyre TM, Prescott SM, Zimmerman GA 1989. Platelet-activating factor acetylhydrolase increases during macrophage differentiation. A novel mechanism that regulates accumulation of platelet-activating factor. J Biol Chem 264: 8467-8470.

Fukuda Y, Kawashima H, Saito K, Inomata N, Matsui M, Nakanishi T 2000. Effect of human plasma-type plateletactivating factor acetylhydrolase in two anaphylactic shock models. Eur J Pharmacol 390: 203-207.

Glauser MP 2000. Pathophysiologic basis of sepsis: considerations for future strategies of intervention. Crit Care Med 28: S4-8.

Graham RM, Stephens CJ, Silvester W, Leong LL, Sturm MJ, Taylor RR 1994. Plasma degradation of platelet-activating factor in severely ill patients with clinical sepsis. Crit Care Med 22: 204-212.

Hattori K, Hattori M, Adachi H, Tsujimoto M, Arai H, Inoue K 1995. Purification and characterization of platelet-activat- 
ing factor acetylhydrolase II from bovine liver cytosol. $J$ Biol Chem 270: 22308-22313.

Hattori M, Adachi H, Tsujimoto M, Arai H, Inoue K 1994. Miller-Dieker lissencephaly gene encodes a subunit of brain platelet-activating factor acetylhydrolase [corrected]. $\mathrm{Na}$ ture 370: 216-218.

Henderson Jr WR, Lu J, Poole KM, Dietsch GN, Chi EY 2000. Recombinant human platelet-activating factoracetylhydrolase inhibits airway inflammation and hyperreactivity in mouse asthma model. J Immunol 164:3360-3367.

Henig NR, Aitken ML, Liu MC, Yu AS, Henderson Jr WR 2000. Effect of recombinant human platelet-activating factor-acetylhydrolase on allergen-induced asthmatic responses. Am J Respir Crit Care Med 162: 523-527.

Heuer HO 1991. Involvement of platelet-activating factor (PAF) in septic shock and priming as indicated by the effect of hetrazepinoic PAF antagonists. Lipids 26: 1369-1373.

Hiramoto M, Yoshida H, Imaizumi T, Yoshimizu N, Satoh K 1997. A mutation in plasma platelet-activating factor acetylhydrolase (Val279 $\longrightarrow$ Phe) is a genetic risk factor for stroke. Stroke 28: 2417-2420.

Honda Z, Nakamura M, Miki I, Minami M, Watanabe T, Seyama $\mathrm{Y}$ et al. 1991. Cloning by functional expression of plateletactivating factor receptor from guinea-pig lung. Nature 349: 342-346.

Howard KM, Olson MS 2000. The expression and localization of plasma platelet-activating factor acetylhydrolase in endotoxemic rats. J Biol Chem 275: 19891-19896.

Howard KM, Miller JE, Miwa M, Olson MS 1997. Cell-specific regulation of expression of plasma-type platelet-activating factor acetylhydrolase in the liver. J Biol Chem 272: 27543-27548.

Ichihara S, Yamada Y, Yokota M 1998. Association of a G994 $\rightarrow$ T missense mutation in the plasma platelet-activating factor acetylhydrolase gene with genetic susceptibility to nonfamilial dilated cardiomyopathy in Japanese. Circulation 98: 1881-1885.

Imaizumi TA, Stafforini DM, Yamada Y, McIntyre TM, Prescott SM, Zimmerman GA 1995. Platelet-activating factor: a mediator for clinicians. J Intern Med 238: 5-20.

Ishii S, Kuwaki T, Nagase T, Maki K, Tashiro F, Sunaga S et al. 1998. Impaired anaphylactic responses with intact sensitivity to endotoxin in mice lacking a platelet-activating factor receptor. J Exp Med 187: 1779-1788.

Karasawa K, Harada A, Satoh N, Inoue K, Setaka M 2003. Plasma platelet activating factor-acetylhydrolase (PAFAH). Prog Lipid Res 42: 93-114.

Lopez Diez F, Nieto ML, Fernandez-Gallardo S, Gijon MA, Sanchez Crespo M 1989. Occupancy of platelet receptors for platelet-activating factor in patients with septicemia. $J$ Clin Invest 83: 1733-1740.

Lorant DE, Patel KD, McIntyre TM, McEver RP, Prescott SM, Zimmerman GA 1991. Coexpression of GMP-140 and PAF by endothelium stimulated by histamine or thrombin: a juxtacrine system for adhesion and activation of neutrophils. J Cell Biol 115: 223-234.

Loucks EB, Symersky P, Qayumi AK 1997. Platelet-activating factor antagonism: a new concept in the management of regional myocardial ischemia-reperfusion injury. J Invest Surg 10: 321-338.

Marathe GK, Davies SS, Harrison KA, Silva AR, Murphy RC, Castro-Faria-Neto $\mathrm{H}$ et al. 1999. Inflammatory plateletactivating factor-like phospholipids in oxidized low density lipoproteins are fragmented alkyl phosphatidylcholines. J Biol Chem 274: 28395-28404.

Martin GS, Mannino DM, Eaton S, Moss M 2003. The epidemiology of sepsis in the United States from 1979 through 2000. N Engl J Med 348: 1546-1554.

Martins MA, Castro Faria Neto HC, Bozza PT, e Silva PM, Lima MC, Cordeiro RS et al. 1993. Role of PAF in the allergic pleurisy caused by ovalbumin in actively sensitized rats. J Leukoc Biol 53: 104-111.

Martins MA, Martins PM, Castro Faria Neto HC, Bozza PT, Dias PM, Cordeiro RS et al. 1988. Intravenous injections of PAF-acether induce platelet aggregation in rats. Eur $J$ Pharmacol 149: 89-96.

Martins MA, Silva PM, Castro Faria Neto HC, Lima MC, Cordeiro RS et al. 1987. Interactions between local inflammatory and systemic haematological effects of PAF-acether in the rat. Eur J Pharmacol 136: 353-360.

Martins MA, Silva PM, Castro Faria Neto HC, Bozza PT, Dias PM, Lima MC et al. 1989. Pharmacological modulation of Paf-induced rat pleurisy and its role in inflammation by zymosan. Br J Pharmacol 96: 363-371.

Mathiak G, Szewczyk D, Abdullah F, Ovadia P, Rabinovici R 1997. Platelet-activating factor (PAF) in experimental and clinical sepsis. Shock 7: 391-404.

McIntyre TM, Zimmerman GA, Prescott SM 1999. Biologically active oxidized phospholipids. J Biol Chem 274: 25189-25192.

Min JH, Wilder C, Aoki J, Arai H, Inoue K, Paul L et al. 2001. Platelet-activating factor acetylhydrolases: broad substrate specificity and lipoprotein binding does not modulate the catalytic properties of the plasma enzyme. Biochemistry 40: 4539-4549.

Minneci PC, Deans KJ, Banks SM, Eichacker PQ, Natanson C 2004. Should we continue to target the platelet-activating factor pathway in septic patients? Crit Care Med 32: 585588.

Miwa M, Miyake T, Yamanaka T, Sugatani J, Suzuki Y, Sakata $S$ et al. 1988. Characterization of serum platelet-activating factor (PAF) acetylhydrolase. Correlation between deficiency of serum PAF acetylhydrolase and respiratory symptoms in asthmatic children. J Clin Invest 82: 1983-1991.

Morgan EN, Boyle EM, Jr., Yun W, Kovacich JC, Canty Jr TG, Chi E et al. 1999. Platelet-activating factor acetylhydrolase prevents myocardial ischemia-reperfusion injury. Circulation 100: II365-368.

Nagase T, Ishii S, Katayama H, Fukuchi Y, Ouchi Y, Shimizu T 1997. Airway responsiveness in transgenic mice overexpressing platelet-activating factor receptor. Roles of thromboxanes and leukotrienes. Am J Respir Crit Care Med 156: 1621-1627.

Nakajima K, Murakami M, Yanoshita R, Samejima Y, Karasawa $\mathrm{K}$, Setaka M et al. 1997. Activated mast cells release extracellular type platelet-activating factor acetylhydrolase that contributes to autocrine inactivation of platelet-activating 
factor. J Biol Chem 272: 19708-19713.

Narahara H, Nishioka Y, Johnston JM 1993. Secretion of platelet-activating factor acetylhydrolase by human decidual macrophages. J Clin Endocrinol Metab 77: 1258-1262.

Narahara H, Kawano Y, Nasu K, Yoshimatsu J, Johnston JM, Miyakawa I 2003. Platelet-activating factor inhibits the secretion of platelet-activating factor acetylhydrolase by human decidual macrophages. J Clin Endocrinol Metab 88 : 6029-6033.

Opal S, Laterre PF, Abraham E, Francois B, Wittebole X, Lowry $S$ et al. 2004. Recombinant human platelet-activating factor acetylhydrolase for treatment of severe sepsis: results of a phase III, multicenter, randomized, double-blind, placebocontrolled, clinical trial. Crit Care Med 32: 332-341.

Pinckard RN, Farr RS, Hanahan DJ 1979. Physicochemical and functional identity of rabbit platelet-activating factor (PAF) released in vivo during $\mathrm{IgE}$ anaphylaxis with PAF released in vitro from IgE sensitized basophils. J Immunol 123: 18471857.

Prescott SM, Zimmerman GA, Stafforini DM, McIntyre TM 2000. Platelet-activating factor and related lipid mediators. Annu Rev Biochem 69: 419-445.

Pritchard PH 1987. The degradation of platelet-activating factor by high-density lipoprotein in rat plasma. Effect of ethynyloestradiol administration. Biochem J 246: 791-794.

Rabinovici R, Yue TL, Farhat M, Smith 3rd EF, Esser KM, Slivjak M et al. 1990. Platelet activating factor (PAF) and tumor necrosis factor-alpha (TNF alpha) interactions in endotoxemic shock: studies with BN 50739, a novel PAF antagonist. J Pharmacol Exp Ther 255: 256-263.

Riedemann NC, Guo RF, Ward PA 2003. The enigma of sepsis. J Clin Invest 112: 460-467.

Satoh N, Asano K, Naoki K, Fukunaga K, Iwata M, Kanazawa $M$ et al. 1999. Plasma platelet-activating factor acetylhydrolase deficiency in Japanese patients with asthma. Am J Respir Crit Care Med 159: 974-979.

Schuster DP, Metzler M, Opal S, Lowry S, Balk R, Abraham E et al. 2003. Recombinant platelet-activating factor acetylhydrolase to prevent acute respiratory distress syndrome and mortality in severe sepsis: Phase IIb, multicenter, randomized, placebo-controlled, clinical trial. Crit Care Med 31: 1612-1619.

Silva PM, Martins MA, Cordeiro RS, Vargaftig BB 1989. Late eosinophil mobilization induced by PAF-acether in the pleural cavity of rats. Braz J Med Biol Res 22: 1281-1285.

Snyder F, Lee TC, Blank M, Malone B, Woodard D, Robinson M 1985. Platelet-activating factor: alternate pathways of biosynthesis, mechanism of inactivation, and reacylation of lyso-PAF with arachidonate. Adv Prostaglandin Thromboxane Leukot Res 15: 693-696.

Stafforini DM 2001. PAF acetylhydrolase gene polymorphisms and asthma severity. Pharmacogenomics 2: 163-175.

Stafforini DM, Prescott SM, McIntyre TM 1987. Human plasma platelet-activating factor acetylhydrolase. Purification and properties. J Biol Chem 262: 4223-4230.

Stafforini DM, McIntyre TM, Carter ME, Prescott SM 1987. Human plasma platelet-activating factor acetylhydrolase. Association with lipoprotein particles and role in the deg- radation of platelet-activating factor. J Biol Chem 262: 42154222.

Stafforini DM, McIntyre TM, Zimmerman GA, Prescott SM 1997. Platelet-activating factor acetylhydrolases. J Biol Chem 272: 17895-17898.

Stafforini DM, McIntyre TM, Zimmerman GA, Prescott SM 2003. Platelet-activating factor, a pleiotrophic mediator of physiological and pathological processes. Crit Rev Clin Lab Sci 40: 643-672.

Stafforini DM, Numao T, Tsodikov A, Vaitkus D, Fukuda T, Watanabe N, et al. 1999. Deficiency of platelet-activating factor acetylhydrolase is a severity factor for asthma. J Clin Invest 103: 989-997.

Stafforini DM, Satoh K, Atkinson DL, Tjoelker LW, Eberhardt C, Yoshida $\mathrm{H}$ et al. 1996. Platelet-activating factor acetylhydrolase deficiency. A missense mutation near the active site of an anti-inflammatory phospholipase. J Clin Invest 97: 2784-2791.

Stremler KE, Stafforini DM, Prescott SM, McIntyre TM 1991. Human plasma platelet-activating factor acetylhydrolase. Oxidatively fragmented phospholipids as substrates. J Biol Chem 266: 11095-11103.

Suputtamongkol Y, Intaranongpai S, Smith MD, Angus B, Chaowagul W, Permpikul C et al. 2000. A double-blind placebo-controlled study of an infusion of lexipafant (Plateletactivating factor receptor antagonist) in patients with severe sepsis. Antimicrob Agents Chemother 44: 693-696.

Tetta C, Mariano F, Buades J, Ronco C, Wratten ML, Camussi G 1997. Relevance of platelet-activating factor in inflammation and sepsis: mechanisms and kinetics of removal in extracorporeal treatments. Am J Kidney Dis 30: S57-65.

Tjoelker LW, Eberhardt C, Unger J, Trong HL, Zimmerman GA, McIntyre TM et al. 1995. Plasma platelet-activating factor acetylhydrolase is a secreted phospholipase A2 with a catalytic triad. J Biol Chem 270: 25481-25487.

Tjoelker LW, Wilder C, Eberhardt C, Stafforini DM, Dietsch G, Schimpf B et al. 1995. Anti-inflammatory properties of a platelet-activating factor acetylhydrolase. Nature 374: 549553.

Unno N, Nakamura T, Kaneko H, Uchiyama T, Yamamoto N, Sugatani J et al. 2000. Plasma platelet-activating factor acetylhydrolase deficiency is associated with atherosclerotic occlusive disease in japan. J Vasc Surg 32: 263-267.

Van Amersfoort ES, Van Berkel TJ, Kuiper J 2003. Receptors, mediators, and mechanisms involved in bacterial sepsis and septic shock. Clin Microbiol Rev 16: 379-414.

Wu X, Zimmerman GA, Prescott SM, Stafforini DM 2004. The p38 MAPK pathway mediates transcriptional activation of the plasma platelet-activating factor acetylhydrolase gene in macrophages stimulated with lipopolysaccharide. $J$ Biol Chem 279: 36158-36165.

Yamada Y, Yokota M 1997. Loss of activity of plasma plateletactivating factor acetylhydrolase due to a novel Gln281 $\longrightarrow$ Arg mutation. Biochem Biophys Res Commun 236: 772775.

Yamada Y, Ichihara S, Fujimura T, Yokota M 1998. Identification of the G994 $\rightarrow$ T missense in exon 9 of the plasma platelet-activating factor acetylhydrolase gene as an inde- 
pendent risk factor for coronary artery disease in Japanese men. Metabolism 47: 177-181.

Yamada Y, Stafforini DM, Imaizumi T, Zimmerman GA, McIntyre TM, Prescott SM 1994. Characterization of the platelet-activating factor acetylhydrolase from human plasma by heterologous expression in Xenopus laevis oocytes. Proc Natl Acad Sci USA 91: 10320-10324.

Yoshida H, Imaizumi T, Fujimoto K, Itaya H, Hiramoto M, Yoshimizu $\mathrm{N}$ et al. 1998. A mutation in plasma plateletactivating factor acetylhydrolase (Val279Phe) is a genetic risk factor for cerebral hemorrhage but not for hypertension. Thromb Haemost 80: 372-375.

Yoshida H, Satoh K, Koyama M, Hiramoto M, Takamatsu S 1996. Deficiency of plasma platelet-activating factor acetylhydrolase: roles of blood cells. Am J Hematol 53: 158-164.

Zimmerman GA, McIntyre TM 2004. PAF, ceramide and pul- monary edema: alveolar flooding and a flood of questions. Trends Mol Med 10: 245-248.

Zimmerman GA, McIntyre TM, Prescott SM 1985. Thrombin stimulates the adherence of neutrophils to human endothelial cells in vitro. J Clin Invest 76: 2235-2246.

Zimmerman GA, Elstad MR, Lorant DE, McLntyre TM, Prescott SM, Topham MK et al. 1996. Platelet-activating factor (PAF): signalling and adhesion in cell-cell interactions. Adv Exp Med Biol 416: 297-304.

Zimmerman GA, McIntyre TM, Mehra M, Prescott SM 1990. Endothelial cell-associated platelet-activating factor: a novel mechanism for signaling intercellular adhesion. J Cell Biol 110: 529-540.

Zimmerman GA, McIntyre TM, Prescott SM, Stafforini DM 2002. The platelet-activating factor signaling system and its regulators in syndromes of inflammation and thrombosis. Crit Care Med 30: S294-301. 
